\title{
Psychometric Properties of Indonesian Version of Athletes Psychological Condition Scale
}

\author{
Kadek Yogi Parta Lesmana ${ }^{1, *}$ Kadek Suranata ${ }^{2}$
}

\author{
${ }^{1}$ Universitas Pendidikan Ganesha \\ ${ }^{2}$ Universitas Pendidikan Ganesha \\ *Corresponding author.Email: yogi.parta@undiksha.ac.id
}

\begin{abstract}
Psychological conditions are one of the aspects that can affect the achievements of athletes by sports in every competition that's allows athletes to achieve glorious performance. This study aims to examine the feasibility and validity of the psychological scale of the Indonesian version of athletes. A total of 92 scale items were developed based on seven theoretical dimensions, namely: (1) attention or focus control, (2) goal setting, (3) self-image, (4) relaxation and activation, (5) selftalk, (6) emotional control, and (7) automation. The assessment of the feasibility of the item content involved three raters. Data for testing the validity of items and scale factors were obtained through an online survey involving 320 athletes in the province of Bali. The first stage analysis of the expert's assessment of the feasibility of item scale items was carried out with the formulation of item feasibility and the scale from the Lawshe's formulation by calculating the CVR of each item and the CVI of the scale. The second stage of analysis was carried out by calculating the validity of items and factors through EFA which was carried out by the JASP program. The study results showed that (1) The results of the CVR analysis showed that 92 items in the inventory of the athlete's psychological factors met a very good CVR value (CVR> 0). Furthermore, the overall validity value was analyzed using CVI (content validity index). The results of the CVI analysis show that the inventory of psychological factors of athletes developed in this study has a CVI value of 0.98 which indicates a special feasibility, (2) from the EFA analysis showed that only 60 of 92 items had a good loading factor and were grouped on two factors or dimensions. The reliability factor of both dimensions is at good reliability, namely in dimension 1 is 0.88 , and factor $\mathbf{2}$ is 0.91
\end{abstract}

Keywords—psychological factors, exploratory factor analysis, confirmatory factor analysis, $R \& D$.

\section{INTRODUCTION}

Psychological, social emotional or often called character is one of the dimensions of the individual that has begun to be noticed recently. This psychological factor is predicted to have contributed about $60-80 \%$ of one's success [1], [2]. In sports achievements achieved by athletes, it is predicted that in addition to physical strength, psychological factors or individual character (psychological, mental, emotional) have an important contribution to athlete's performance. This is evidenced by the results of research which have shown that non-cognitive factors as psychological abilities and character contribute very high to the success of athletes in achieving brilliant achievements [3]-[11]. This is reinforced by the finding that the appearance of athletes in games or competitions cannot be separated from their behavior and underlying psychological aspects [12].

So far, athletes who will compete in championships tend to focus more on physical strength training, while psychological aspects are often left aside [13]. In fact, there are not a few athletes who are unable to achieve maximum performance due to mental, emotional or other psychological factors, such as experiencing anxiety [14]; low self-esteem and motivation [15], or other psychological disorders.

The term non-cognitive abilities that represent individual psychological abilities became popular when Heckman and Rubenstein [16] won the Nobel Prize in Economics; which states that a person's success is not only determined by how he / she mastered knowledge and technical skills, but noncognitive factors, such as motivation, time management skills, self-regulation, resilience, social emotional, are critical factors that are not less important. determine one's success. A year later, Lamb found 10 important abilities that a person must have in the 21 st century where the 5 proposed abilities are non-cognitive abilities, namely creativity, motivation, selfefficacy, caution and responsibility (conscientiousness), as well as persistence (grit)[16].

Studies and research on non-cognitive abilities continue to develop and produce new non-cognitive variables adds the locus of control factor as a crucial non-cognitive ability that must exist in a person in the 21st century[17]. Prior to that, developed countries such as the United States and other developed countries in the European continent had emphasized the importance of 3 non-cognitive variables [18], such as adaptability, curiosity and grit.

In the last two decades there have been many studies that have produced psychological instruments or scales to determine the psychological condition of athletes, including: The Psychological Performance Inventory (PPI) is designed to assess mental strengths and weaknesses [19] on a profile that combines seven factors, namely: self-confidence, negative energy, attention control, visuals and images control, motivation level, positive energy and attitude control. The PPI is one instrument to include items that describe the specific psychological behavior of athletes to increase athletes' awareness and understanding of their mental skills. Although it has been used by consultants as an assessment tool in applied settings, little research has been done on the validity and reliability of PPIs, and has not been widely used as a research tool in psychological interventions.

Another popular instrument is called the Psychological Skills Inventory for Sport (PSIS) [20]. The PSIS was developed in an attempt to assess relevant psychological skills with outstanding athletic performance. The original PSIS 
consisted of 51 true or false items that were developed to identify differences in the use of psychological skills by professional athletes, and aspiring college athletes.

Another newer instrument is the Athletic Coping Skills Inventory-28 (ACSI) [21]. This inventory was developed from the original Coping Skill Inventory, which was designed to assess the psychological skills athletes use to manage their performance. This results in a total score of Personal Coping Resources, which is assumed to reflect the athletes' diverse psychological skill constructs.

The development of standard instruments and fulfilling the feasibility of psychometric as valid instruments on noncognitive aspects of athletes is still limited. So it is necessary to develop a proper inventory in accordance with psychometric principles related to non-cognitive aspects or factors that affect athletes' achievement. Therefore, this study aims to develop an inventory of psychological factors that affect athletes' performance.

\section{METHOD}

\section{A. Research Subject}

The subjects in this study were 320 athletes from all districts and cities in Bali Province. The classification and condition of the respondents are (1) in terms of gender, the proportion of women and men is quite representative with a ratio of $57 \%$ : $42 \%$, (2) in terms of age, respondents in this study varied, but the dominant age was adolescents with a range of 14-20 years old, (3) in terms of education, respondents in this study were dominated by athletes who had the latest education at the SMA / SMK levels, (4) in terms of the types of sports they are engaged in, respondents in this study were athletes from sports that various, (5) in terms of the level of competitions that have been participated in, the respondents in this study each had experience participating in competitions at the local, national, and international levels.

\section{- B. Research Design}

This study is a research and development (R\&D) which aims to develop an inventory of psychological factors that affect athlete's performance. The stages of this research include

(1) formulation of dimensions / factors, indicators, and blueprint inventory for each theoretical psychological factor that affects athletes' performance, (2) compilation of statement items on each dimension and indicators based on the blue print developed, (3) theoretical validity tests involving three expert, (4) analysis of theoretical validity tests results, (4) empirical trials through surveys (5) analysis of empiric trials results.

\section{Data Collection}

The content validity test data in this study were obtained through content validity sheets filled in by three experts. Meanwhile, the data for construct validity testing were obtained through online surveys. The online survey was conducted via online method of survey was perform by Google. The survey

form can be accessed on the page https://forms.gle/Wh7ijFyoiXysKqCM6. The survey was conducted from the beginning of February to June 2020, overall the number of respondents who have filled out the form completely is 320 respondents. This number has met the target number of respondents to be obtained.

\section{Data Analysis}

Data from the content validity sheet that had been responded by three experts (expert judgment) were analyzed to determine the content validity of the inventory of athlete's psychological factors using the content validity ratio (CVR) and the content validity index (CVI) [22]. Furthermore, the data from the inventory trial results through an online survey were analyzed using exploratory factor analysis (EFA) using the JASP program to determine the construct validity of the inventory of psychological factors for athletes developed in this study.

\section{RESULTS AND DISCUSSION}

\section{A. Results}

The content validity test of the inventory of psychological factors for athletes in this study was carried out using a content validation sheet that was assessed by 3 experts / practitioners (expert judgment). The results of expert judgment were analyzed in order to prove the feasibility of each item on the psychological scale of the athlete. The results of responses by three experts to each item on the validity test sheet were analyzed using the content validity ratio (CVR)[22]. The results of the CVR analysis show that 92 items in the inventory of athlete's psychological factors fulfill a very good CVR value (CVR> 0). Furthermore, the overall validity value was analyzed using the content validity index (CVI) [22]. The results of the CVI analysis indicate that the inventory of psychological factors for athletes developed in this study has a CVI value of 0.98 which indicates a special feasibility value. With these results, all items in the inventory of athlete's psychological factors developed in this study have met the content validity criteria so that they can be tested further.

The results of inventory trials conducted through an online survey involving 320 athletes as respondents were analyzed by exploratory factor analysis (EFA) using the JASP program to determine the construct validity of the inventory of psychological factors for athletes developed in this study. The first phase of EFA (92 items, $n=320$ ) showed the KaiserMeyer-Olkin (KMO) is 0.923 and the Barlett's test was Significant $(\mathrm{p}<0,001)$, dicatin that the sample size dequancy. In this first phase, there are several items that show that the Anti-image Matrices value is not in accordance with what is required $(>0.5)$ so that it is tested again. The fourth round factor analysis (using 60 items) showed that the KaiseeMeyer-Olkin test (KMO) value was 0.941 and Barlett's test value was significant $(\mathrm{p}<0.001)$. The anti-image matrices value on all items (60 items) is above 0.5 . Thus, the factor analysis in the fourth phase using 60 items has met the prerequisites for exploratory factor analysis testing.

If the findings of this study are related to the conceptual basis of psychological factors, the findings in this study are in line with the development of an inventory of measures of noncognitive factors among athletes known as The Test of Performance Strategies (TOPS) [8]. If in the inventory of psychological factors developed in this study, there are 2 psychological dimensions measured, namely self-control and self-awareness, TOPS measures seven non-cognitive dimensions, namely (1) controlling attention or focus, (2) setting goals, ( 3) self-image, (4) relaxation and activation, (5) self-talk, (6) emotional control, and (7) automation. 
45 items and factor 2 is formed by 15 items with significant factor loading value

The next step is an assessment of the formed factors which are summarized and can be accessed on this page https://www.osf.io/p8adu. The interpretation of the two-factor forming items is based on significant factor loading, where items that have a loading factor $<0.5$ are not written. Each factor is named based on the items that make up it. Factor 1 is formed by 45 items while factor 2 is formed by 15 items. The determination of the number of factors is carried out based on figure 1 .

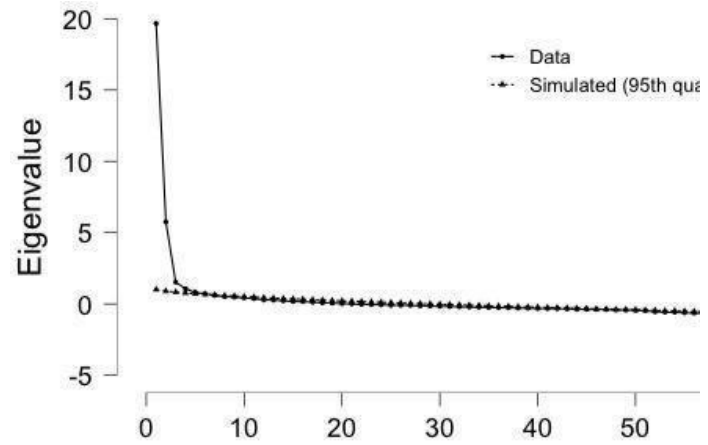

Fig. 1. Scree Plot

Furthermore, the items forming the two factors are illustrated in Figure 2.

Factor 1 is named the self-control factor formed by 45 items with each forming item number as shown in Figure 2. Factor 2 is named the self-awareness factor formed by 15 items with each forming item number as shown in figure 2 .

\section{B. Discussion}

The results of the validation of the inventory content of the psychological factors of athletes developed in this study indicate that the inventory has met the theoretical feasibility criteria. The results of the construct validation of the inventory

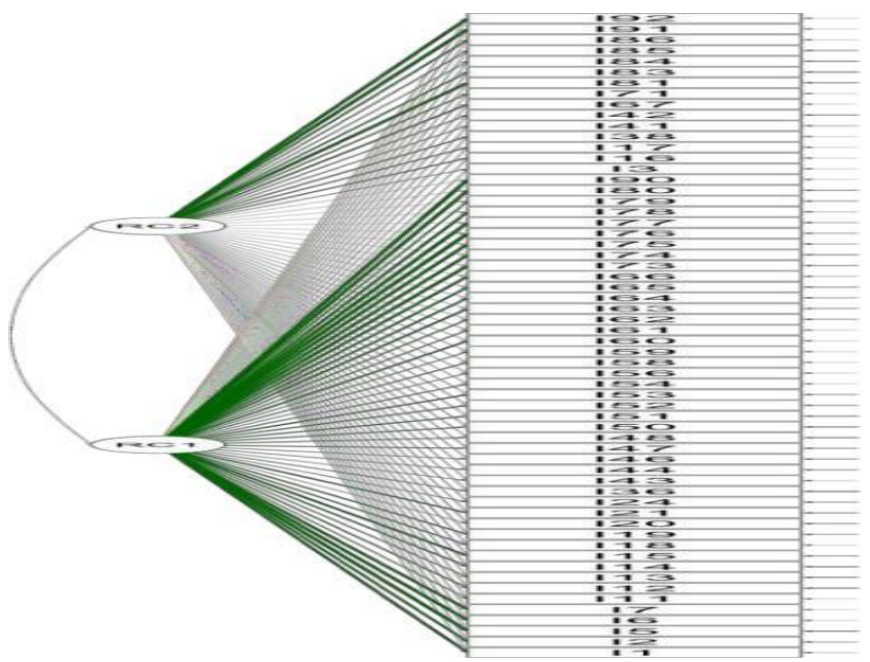

Fig. 2. Path Diagram
In addition to the seven non-cognitive factors stated, endurance and persistence (grit) are seen as important factors for athletes [23]. The ability to be diligent, resilient, or known as Grit, makes athletes always try, train, not afraid to lose, or bounce back after defeated [24].

This study has limitations because the sample used only involved athletes from the province of Bali. To get a more varied response, further research needs to involve a larger population of athletes and cover a wider area.

\section{CONCLUSION}

The results of this study indicate that the inventory of psychological factors for athletes developed in this study have met the criteria of theoretical and empirical validity. The CVR analysis showed that 92 items in the inventory of the athlete's psychological factors met a very good CVR value (CVR>0). Furthermore, the overall validity value was analyzed using CVI (content validity index). The results of the CVI analysis show that the inventory of psychological factors of athletes developed in this study has a CVI value of 0.98 which indicates a special feasibility. The CFA analysis showed that only 60 of 92 items had a good loading factor and were grouped on two factors or dimensions. From the fourth round of EFA showed that the Kaisee-MeyerOlkin test (KMO) value was 0.941 and Barlett's test value was significant $(\mathrm{p}<0.001)$. The anti-image matrices value on all items (60 items) is above 0.5 . Thus, the factor analysis in the fourth phase using 60 items has met the prerequisites for exploratory factor analysis testing. The reliability factor of both dimensions is at good reliability, namely in dimension 1 is 0.88 , and factor 2 is 0.91 .

\section{ACKNOWLEDGMENT}

This research was conducted with funding from a research grant from the DIPA Ganesha University of Education, Bali, Indonesia. Thanks are conveyed to athletes throughout Bali Province who have been willing to assist in this research process as respondent.

\section{REFERENCES}

[1] E. Garcia, "The need to address non-cognitive skills in the education policy agenda.," in Non-cognitive skills and factors in educational attainment, BrillSense, 2016, pp. 31-64.

[2] D. Goleman, What Makes a Leader. Harvard Business Review Classics, 2003.

[3] M. Browne and M. Mahoney, "Sport psychology," Annu. Rev. Psychol., vol. 35, pp. 60-62, 1984.

[4] M. Mahoney, "Cognitive skills and athletic performance," in Cognitive-behavioral interventions: theory, research and procedures, New York: Academic Press, 1979, pp. 423-443.

[5] M. Mahoney, "Clinical sport psychology," Clin. Psychol., vol. 39, no. 3, pp. 64-80, 1986.

[6] J. Silva and R. Weinberg, Psychological foundations of sports. Champaign, IL: Human Kinetic, 1984. 
[7] G. Dale, "Existential phenomenology: Emphasizing the experience of the athlete in sport psychology research," Sport Psychol., vol. 10, no. 4, pp. 307-321, 1996.

[8] R. T. Patrick, M. Shane, and L. Hardy, "Test of performance strategies: Development and preliminary validation of a comprehensive measure of athletes' psychological skills," J. Sports Sci., vol. 17, no. 9, pp. 697-711, 1999.

[9] C. Swann, A. Moran, and D. Piggott, "Defining elite athletes: Issues in the study of expert performance in sport psychology," Psychol. Sport Exerc., vol. 16, pp. 3-14, 2015.

[10] H. Effendi, "Peranan psikologi olahraga dalam meningkatkan prestasi atlet," Nusant. J. Ilmu Pengetah. Sos., vol. 1, no. 1, 2016.

[11] T. Hastuti, "Karakteristik Psikologis Atlet di Pusat Pendidikan danLatihan Pelajar (PPLP)," J. Psikol., vol. 40, no. 2, pp. 143-158, 2013.

[12] S. Lamb, M. Quentin, and D. Esther, Key skills for the 21st Century: an evidence-based review. Education Future Frontiers., 2017.

[13] C. Y, Y. Lu, and H. Xie, Education and non-cognitive skills. National University of Singapora, 2018.J.

[14] Egalite, Anna, N. Mills, G. Jonathan, and P. Jay, The softer side of learning: measuring student's noncognitive skills. 2015

J. Loehr, Mental Toughness Training for Sports: Achieving Athletic Excellence. Lexington, MA: Stephen Greene Press, 1986.

M. Mahoney, T. Gabriel, and T. Perkins,

"Psychological skills and exceptional athletic performance.," Sport Psychol., vol. 1, pp. 181-199, 1987.

[15] R. Smith, R. Schutz, F. Smoll, and J. Ptacek, “).

Development and validation of a multidimensional measure of sport psychological skills: The Athletic Coping Skills Inventory," J. Sport Excercise Psychol., vol. 17, pp. 379-398, 1995.

[16] C. H. Lawshe, "a Quantitative Approach To Content Validity,” Pers. Psychol., vol. 28, no. 4, pp. 563-575, 1975.

[17] T. Moles, A. Auerbach, and T. Petrie, "Grit happens: Moderating effects on motivational feedback and sport performance," J. Appl. Sport Psychol., vol. 29, no. 4, pp. 418-433, 2017.

[18] V. Ramadian, "Studi Deskriptif Mengenai Grit pada Atlet Bulutangkis di "Pusdiklat Perkumpulan Bulutangkis" X Bandung," Universitas Kristen Mara, 2018 